\title{
Tertiary Lymphoid Structures in Colorectal Cancer Liver Metastases: Association With Immunological and Clinical Parameters and Chemotherapy Response
}

\author{
AZAZ AHMED ${ }^{1,2}$ and NIELS HALAMA ${ }^{1,2,3}$ \\ ${ }^{1}$ German Cancer Research Center (DKFZ), Department of Translational Immunotherapy, Heidelberg, Germany; \\ ${ }^{2}$ National Center for Tumor Diseases, Heidelberg, Germany; \\ ${ }^{3}$ Helmholtz Institute for Translational Oncology (HI-TRON), Mainz, Germany
}

\begin{abstract}
Background/Aim: The presence of TLS (tertiary lymphoid structures) is detectable in the microenvironment of human cancers and linked to better patient outcomes. The role of TLS in colorectal cancer liver metastases (CRCLM) is unclear. Patients and Methods: Medical records of patients with CRCLM were reviewed $(n=33)$ and corresponding tissue samples $(n=21)$ were obtained. Whole slide imaging analyses on immunohistochemical staining of immune cell infiltrates and TLS were correlated to clinical outcomes (including chemotherapy response) and other parameters. Results: Neither the size $(p=0.6)$ nor the quantity ( $p=0.47)$ of TLS was associated with the clinical course. When considering spatial differences, TLS in the invasive margin (IM) were associated with progression-free survival ( $p=0.03$ ), while TLS in the LM (liver metastasis) were not. Also, TLS in the IM were associated with the presence of $\mathrm{CD}^{+} \mathrm{T}$ cells, which itself was prognostically favorable $(p<0.001)$. Conclusion: TLS in the IM are associated with good prognosis in CRCLM, but not chemotherapy response.
\end{abstract}

The co-occurrence of tumor-associated $\mathrm{CD}^{+} / \mathrm{CD}^{+} \mathrm{T}$ cells and antigen-presenting cells like $\mathrm{CD} 20^{+} \mathrm{B}$ cells or dendritic celllysosomal associated membrane protein $(\mathrm{DC}-\mathrm{LAMP})^{+}$cells in tertiary lymphoid structures (TLS) is associated with improved survival in malignant melanoma and lung cancer, independently of other clinical variables (1-3). Further, the sheer observation

This article is freely accessible online.

Correspondence to: Niels Halama, MD, Translational Immunotherapy, German Cancer Research Center (DKFZ), Im Neuenheimer Feld 280, 69120 Heidelberg, Germany. Tel: +49 62215638399, Fax: +49 6221567030, e-mail: niels.halama@nctheidelberg.de

Key Words: Tertiary lymphoid structure, colorectal cancer metastases, chemotherapy. of the formation of TLS in tumor tissues and in adjacent normal tissue is a positive prognostic sign (4-6). Also, an association with response to immunotherapy has been reported for malignant melanoma and sarcoma $(7,8)$. In lung cancer, an association between TLS presence and an improved overall clinical course has been shown (3). There are still, however, some important questions that have not been answered, including: a) whether TLS are not only associated with a good prognosis in primary tumors but also in metastatic tumors, b) whether TLS are associated with other immunological or clinical parameters and c) whether TLS are associated with response to chemotherapy. The latter is associated with the immunological context in colorectal cancer liver metastases (CRCLM) (9, 10), and presence or absence of TLS might also play an important role. Metastatic colorectal cancer (mCRC) is still a devastating disease, with the liver being the most frequent site of distant metastases (11). In $20 \%$ of patients, liver metastases can be resected with curative intent (12). Neoadjuvant treatment can improve resectability, but the majority of patients have nonresectable liver metastases and receive palliative chemotherapy (13). The overall prognosis of patients receiving systemic palliative chemotherapy is very limited with a median overall survival of approximately 24-30 months (14). Biomarkers which help selecting patients that are likely to respond to chemotherapy include the effector T cell density ( 9 , 10). Immune cells infiltrating or surrounding colorectal primary tumors and especially tumor-infiltrating lymphocytes (TIL) represent important prognostic factors $(4,6,15)$. High densities of TILs have been shown to be correlated with an improved survival in patients with primary CRC (16). In metastatic lesions, the impact of immune infiltrates on the clinical course and response to chemotherapy has been previously shown $(10,17)$. Here, we analyzed the presence of TLS in CRCLM by quantitatively measuring TLS nodes, their surface area metrics and spatial distribution within the context of CRCLM (intratumoral or at the invasive margin), and comparing these characteristics to other immunological and clinical parameters as 
Table I. Patient characteristics. All patients had liver metastases (M1) at the time of analysis. TNM of initial diagnosis is also shown, as well as localization of primary tumor, chemotherapy regimen, KRAS/BRAF status and utilization of therapeutic antibodies (either anti-VEGF or anti-EGFR)

\begin{tabular}{|c|c|c|c|c|c|c|}
\hline Gender & TNM & Age & Localization & Chemotherapy & KRAS/BRAF & Antibody \\
\hline Male & pT3 pN2(9/22) M1 GII & 55 & Rectum & Irinotecan-based & wt & Yes \\
\hline Male & pT3 pN1(2/13) M1 GII & 55 & Sigmoid & Oxaliplatinum-based & wt & Yes \\
\hline Female & pT2 pN0 M0 GII & 70 & Sigmoid & Oxaliplatinum-based & wt & Yes \\
\hline Female & pT3 pN2 (4/14) L1 M1 GII & 71 & Transversum & Irinotecan-based & wt & Yes \\
\hline Male & pT4 pN2 V1 pM1 GIII & 57 & Rectum & Irinotecan-based & wt & Yes \\
\hline Male & pT4 pN1 M1 & 59 & Transversum & Irinotecan-based & wt & Yes \\
\hline Male & pT2 N0 M1 GII & 69 & Rectum & Oxaliplatinum-based & wt & Yes \\
\hline Male & pT3 pN1 (3/16) M1 GII & 73 & Rectosigmoid & Irinotecan-based & wt & No \\
\hline Male & pT3 pN2 (8/36) M1 GII & 63 & Rectum & Irinotecan-based & Unknown & No \\
\hline Male & pT3 pN1 (2/16) M1 GII & 48 & Ascending & Irinotecan-based & KRAS mut & No \\
\hline Male & pT3 pN2 pM1 & 54 & Sigmoid & Irinotecan-based & wt & Yes \\
\hline Male & pT2 pN1 (1/13) pM1 L1 GII & 40 & Sigmoid & Oxaliplatinum-based & wt & Yes \\
\hline Female & pT3 pN2 (13/28) L1 M1 GIII & 41 & Ascending & Irinotecan-based & KRAS mut & Yes \\
\hline Male & pT4 pN0 M0 GII & 67 & Ascending & Irinotecan-based & wt & No \\
\hline Male & pT3 pN2 pM1 GII & 58 & Ascending & Irinotecan-based & wt & No \\
\hline Male & pT3 pN2 $(15 / 15)$ pM1 GII & 67 & Rectum & Irinotecan-based & wt & Yes \\
\hline Male & pT3 pN1 (1/22) L1 V1 M0 GI-II & 61 & Ascending & Irinotecan-based & wt & Yes \\
\hline Female & pT3a pN0 (0/15) L0 M0 GII & 75 & Ascending & Oxaliplatinum-based & Unknown & No \\
\hline Female & pT3 pN1 M0 GIII & 80 & Sigmoid & Oxaliplatinum-based & wt & No \\
\hline Female & pT4 N0 M0 GIII & 46 & Rectum & Irinotecan-based & wt & Yes \\
\hline Female & pT3 cN2 M1 & 46 & Sigmoid & Irinotecan-based & KRAS mut & Yes \\
\hline
\end{tabular}

well as analyzing the differentiating power of TLS for the clinical course of CRCLM. The utilized patient cohort has been described previously and allows systematic assessment of treatment responses, as these patients were incompletely resected and received systemic therapy (mostly palliative).

\section{Patients and Methods}

Study design and concept. The details have been previously reported (10). In short, records of patients with metastatic CRC who received a diagnostic excision (or primary resection) of liver metastases between the years 1998 and 2008 were reviewed, and informed consent from all patients was obtained. Corresponding tissue samples were analyzed for immune cell infiltrates automatically (18, 19) and correlated with other parameters, e.g. response to chemotherapy. For all 33 patients, detailed follow-up, including progression-free survival under chemotherapy, was available, and for this study, material from 21 patients was available.

Clinical data. The study received approval by the local ethics committee (207/2005). Progression-free survival was defined as the time from the beginning of palliative chemotherapy until disease progression (failure). No patient died during the observed period. Follow-up for each patient included the complete time period until remission or disease progression occurred and encompassed also overall survival. Patients with stage IV CRC were included, after metastatic disease was histologically proven (Table I). All patients received (palliative) chemotherapy, which began within 8 weeks after diagnosis. Patients in this study are from a rare, but clinically highly informative, subgroup among all patients with CRC. Available material from lung metastases was used for reference (to compare structural differences). Other patient inclusion criteria were a Karnofsky performance score of at least $80 \%$, and adequate hepatic, renal, and bone marrow function. Patients with synchronous liver metastasis were included if the primary tumor had been resected prior to chemotherapy. Response to chemotherapy was evaluated according to Response Evaluation Criteria in Solid Tumors (RECIST), every 4-6 cycles. Here, response was defined as partial (or complete) remission or progressive disease. Patients with stable disease after initiation of chemotherapy were further monitored under continued treatment until either disease progression or remission occurred. Radiologic imaging review after at least eight weeks of treatment was performed by "blinded" radiologists or as reported previously (3) and best responses were evaluated. All tumor samples were analyzed for microsatellite instability using the polymorphic markers BAT25, BAT26, and CAT25 as described earlier (20), and all metastases showed microsatellite stability.

Immunohistochemical staining. Tissue samples were immunostained and analyzed for infiltration with CD3, CD8 and granzyme B-positive T cells. Additionally, CD20 and DC-LAMP staining was performed as indicated. Tissue sections $(4 \mu \mathrm{m})$ were generated from formalin-fixed, paraffin-embedded tissues. After deparaffinization and rehydration, slides were boiled in $10 \mathrm{mmol} / \mathrm{l}$ citrate buffer $(\mathrm{pH} 6)$ for $15 \mathrm{~min}$ for antigen retrieval. Endogenous peroxidase activity was blocked by incubating with $\mathrm{H}_{2} \mathrm{O}_{2}(0.6 \%)$ in methanol for 20 min. Blocking with $10 \%$ normal horse serum (VECTASTAIN Elite ABC kit; Vector Laboratories, Burlingame, CA, USA) was then performed. Mouse monoclonal antibodies recognizing human $\mathrm{CD} 3 \mathrm{e}$ (1:50 dilution; clone PS1; Acris, Rockville, MD, USA), CD8 (1:40 dilution; clone 4B11; Novocastra, Wetzlar, Germany), GrB (1:50 dilution; clone 11F1; Novocastra), FOXP3 (1:100 dilution; clone 236A/E7; Abcam, Cambridge, UK) CD20 (clone NCL-L_CD20_L26, dilution 1:100; 
retrieval with citrate buffer, Novocastra) and DC-LAMP (clone IM3446, dilution 1:100, Beckman-Coulter, Brea, CA, USA) were applied as primary antibodies at room temperature $(2 \mathrm{~h})$. Incubation with a biotinylated secondary antibody (1:50 dilution; horse-antimouse IgG; VECTASTAIN Elite ABC kit; Vector Laboratories) for 30 $\mathrm{min}$ at room temperature was followed and then, the $\mathrm{ABC}$ reagent was applied according to the manufacturer's instructions (VECTASTAIN Elite ABC kit; Vector Laboratories). The antigen detection was conducted by a color reaction with 3,30-diaminobenzidine (DAB p chromogen; Dako Cytomation, Santa Clara, CA, USA). The sections were counterstained with hematoxylin (AppliChem, Darmstadt, Germany) and mounted with Aquatex (Merck, Darmstadt, Germany).

Evaluation of immunohistochemical variables. Positively stained immune cells were counted after digitizing the section (NDP Nanozoomer, Hamamatsu Photonics, Hamamatsu City, Shizuoka, Japan). Full tissue sections allow large scale histologic evaluation with high precision across the complete section, minimizing bias due to heterogeneity. Average cell densities across the measured region were used for analysis. The invasive margin was defined as a region of 500 $\mu \mathrm{m}$ width on each side of the border between malignant cells ("metastasis" and peritumoral stroma) and liver tissue $(18,20)$. Manual evaluation of stained immune cells (17-19) was conducted (in duplicates) by two independent observers without knowledge of the clinicopathologic data. Variations in the enumeration within a range of $5 \%$ were reevaluated and a consensus decision was made. The results were expressed as the mean of positive stained cells per $\mathrm{mm}^{2}$. A total of $1,002 \mathrm{~mm}^{2}$ of tissue surface area was analyzed. Tissue surface areas were quantified using the Nanozoomer NanoView tool. Spatial registration of TLS localization was performed manually. All evaluations were visually checked for consistency.

Statistical analyses. Survival curves were computed using the Kaplan-Meier estimator. To investigate correlations between different parameters, Spearman's rank correlation was used. All statistical analyses were conducted with $\mathrm{R}$ version 4.0.2.

\section{Results}

Morphological features of TLS in colorectal cancer liver metastases. Previous work on TLS in lung cancer and melanoma, have highlighted the presence of antigen-presenting cells within the TLS, with DC-LAMP ${ }^{+}$or $\mathrm{CD} 20^{+}$cells being their core elements. While these descriptions nicely underscored the hierarchical structure of the TLS, our investigation shows that the specific distribution patterns of TLS and their numbers and sizes in CRCLM are different (Figure 1A and B). Here, the $\mathrm{DC}-L A M P^{+}$cells (being mainly mature dendritic cells) were identified, but they reside almost exclusively outside of the TLS ( 0 of 29 TLS positive for the presence of DC-LAMP ${ }^{+}$cells) (Figure 1C). The CD20 ${ }^{+} \mathrm{B}$ cells, as antigen-presenting cells, show complex patterns in CRCLM and have a lower frequency $\left(\mathrm{CD} 20^{+} / \mathrm{CD}^{+}\right.$cells showing a median of 1.5:100). Nevertheless, they are present in TLS, mainly outside of the CRCLM, in the invasive margin (Figure 1D). These morphological differences (comparing CRCLM to the other abovementioned entities) point to possible functional differences.
Association between overall survival (OS), progression-free survival (PFS) and the presence of TLS. Previous work has shown direct correlation between the density of $\left(\mathrm{CD}^{+}\right) \mathrm{T}$ cells and the clinical course of the disease. This is also reflected in our cohort (Figure 2A). TLS (independent of T cell densities) did not prove to be a favorable parameter (Figure 2B).

The fact that TLS can have different sizes, prompted us to investigate whether larger TLS have a greater impact on the immunological landscape and patient outcomes. Using the median of the observed surface areas of identified TLS, we detected no difference in the association with the clinical course (PFS or OS) (Figure 2C).

However, by stratifying for the sole presence of TLS within the CRCLM, CRCLM and IM, and only IM, a discernible difference between the three strata was identified for PFS (Figure 2D).

Associations of the presence of TLS with clinical or immunological parameters. Correlating the number and the size of TLS with other parameters revealed that TLS numbers were associated with the density of $\mathrm{CD}^{+} \mathrm{T}$ cells. Other factors like age, gender, KRAS mutation status or nodal status were not associated with the presence of TLS (Table II).

Chemotherapy response and the presence of TLS. The density of $\mathrm{CD}^{+} \mathrm{T}$ cells is not only associated with the clinical outcome (as shown), but also with the response to chemotherapy. We investigated whether the presence of TLS in CRCLM is predictive for the response to chemotherapy. Neither the number nor the size of TLS showed a relevant association with treatment outcome. Regardless of treatment type (chemotherapy with/without antibody), TLS presence was only weakly associated with beneficial outcomes.

\section{Discussion}

The role of the immune system in solid tumors is very complex. Certain cell types are associated with a better survival or their presence is linked to a high success rate of immunotherapy $(21,22)$. In this complexity, immunological structures have been proven to be of critical importance for immunotherapy, which was only highlighted recently. Earlier reports showed that better survival is associated with the presence of TLS in the lung, highlighting that not only the number of immune cells is relevant but also the spatial proximity of specialized subpopulations of immune cells within the TLS is an indicator of clinical outcome $(3,23,24)$. This composition of immunological cells within TLS supports their function, where antigen-presentation is coupled to activation of specific effector $\mathrm{T}$ cells. Therefore, the spatial organization pattern has a value as a biomarker beyond the sheer densities of the involved cells. While, especially effector $\mathrm{T}$ cells are associated with OS and PFS, and their densities are linked to 
A

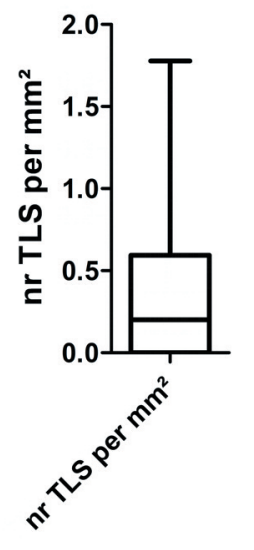

B

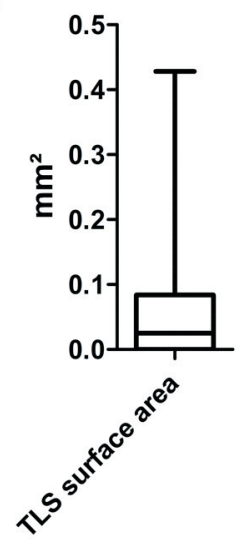

C

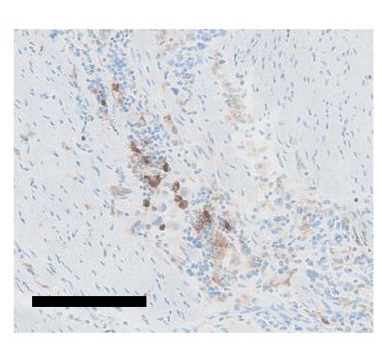

D

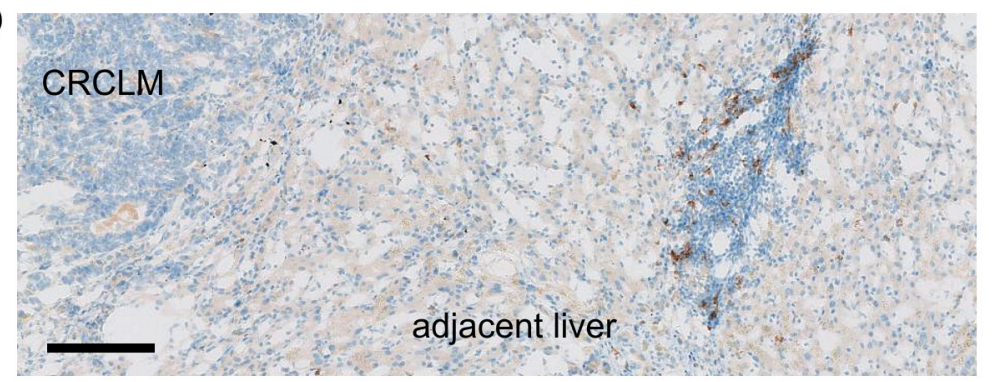

Figure 1. Properties of tertiary lymphoid structures (TLS). (A) Number of TLS per patient sample (normalized to $\mathrm{mm}^{2}$ ) and (B) distribution of surface areas of single TLS. (C) Dendritic cell-lysosomal associated membrane protein (DC-LAMP) stained in colorectal cancer liver metastases $(C R C L M)$ (bar $100 \mu \mathrm{m})$, showing no overt association to TLS and (D) CD20 stained sample highlighting the presence of positive cells mainly in TLS at the invasive margin and not within the CRCLM.

Table II. Correlation coefficient $r$ for different parameters. Bold indicates corresponding p-values $<0.05$.

\begin{tabular}{|c|c|c|c|c|c|c|c|c|c|c|c|}
\hline & CD3 & TLS@IM & Area TLS & TLS nr & Response & RAS status & Age & Gender & $\mathrm{N}+$ & $\mathrm{CD} 8 / \mathrm{CD} 3$ ratio & CD8 \\
\hline CD3 & & 0.59 & -0.01 & -0.03 & 0.70 & 0.13 & 0.13 & 0.18 & -0.30 & 0.05 & 0.31 \\
\hline TLS@IM & 0.59 & & 0.09 & 0.12 & 0.38 & 0.30 & 0.07 & 0.36 & -0.15 & 0.36 & 0.42 \\
\hline Area TLS & -0.01 & 0.09 & & 0.98 & -0.10 & 0.04 & 0.01 & 0.30 & 0.37 & 0.04 & -0.09 \\
\hline TLS nr & -0.03 & 0.12 & 0.98 & & -0.10 & 0.07 & 0.01 & 0.28 & 0.32 & 0.04 & -0.10 \\
\hline Response & 0.70 & 0.38 & -0.10 & -0.10 & & -0.13 & 0.18 & 0.32 & -0.32 & 0.25 & 0.39 \\
\hline RAS status & 0.13 & 0.30 & 0.04 & 0.06 & -0.13 & & -0.51 & -0.33 & 0.25 & -0.01 & 0.03 \\
\hline Age & 0.13 & 0.07 & 0.01 & 0.01 & 0.18 & -0.51 & & -0.13 & -0.31 & -0.07 & -0.04 \\
\hline Gender & 0.18 & 0.36 & 0.30 & 0.27 & 0.32 & -0.32 & -0.13 & & 0.14 & 0.48 & 0.43 \\
\hline $\mathrm{N}+$ & -0.30 & -0.15 & 0.37 & 0.32 & -0.32 & 0.25 & -0.30 & 0.14 & & 0.42 & 0.29 \\
\hline $\mathrm{CD} 8 / \mathrm{CD} 3$ ratio & 0.05 & 0.36 & 0.04 & 0.04 & 0.25 & -0.01 & -0.07 & 0.48 & 0.42 & & 0.94 \\
\hline CD8 & 0.31 & 0.42 & -0.09 & -0.10 & 0.39 & 0.02 & -0.04 & 0.43 & 0.29 & 0.94 & \\
\hline
\end{tabular}

the response to chemotherapy in $\operatorname{CRCLM}(9,18,25)$, their role in metastatic sites remains unclear and has not been previously systematically analyzed. Furthermore, many associations of TLS to clinical and immunological parameters in the metastatic setting are elusive. Are TLS independent of the general T cell infiltration? Is the absence or presence of TLS linked to the clinical course? In the limited set of samples presented here, a link between general $\mathrm{CD}^{+} \mathrm{T}$ cell density and OS was found. This is in line with previous observations and findings from primary tumors $(21,22)$. However, simply the presence of TLS is not obviously correlated with OS or PFS. Using the median quantity of TLS to dichotomize the cohort, higher quantities of
TLS were not found to be associated with clinical benefits. Similarly, the size of TLS was also not found to be linked to clinical benefit. In order to differentiate the role of TLS in more detail, the presence of TLS within metastatic lesions, the invasive margin or both was analyzed. Here, a difference in PFS was noted. This suggests that the composition of subcompartments, i.e. the invasive margin, is relevant for the indepth evaluation of metastatic lesions and larger cohorts are needed to corroborate these findings. This would also indicate that not only the number or size of the TLS is important, but also the precise localization (limited to the invasive margin) is beneficial for the patient. In addition, it needs to be pointed out 

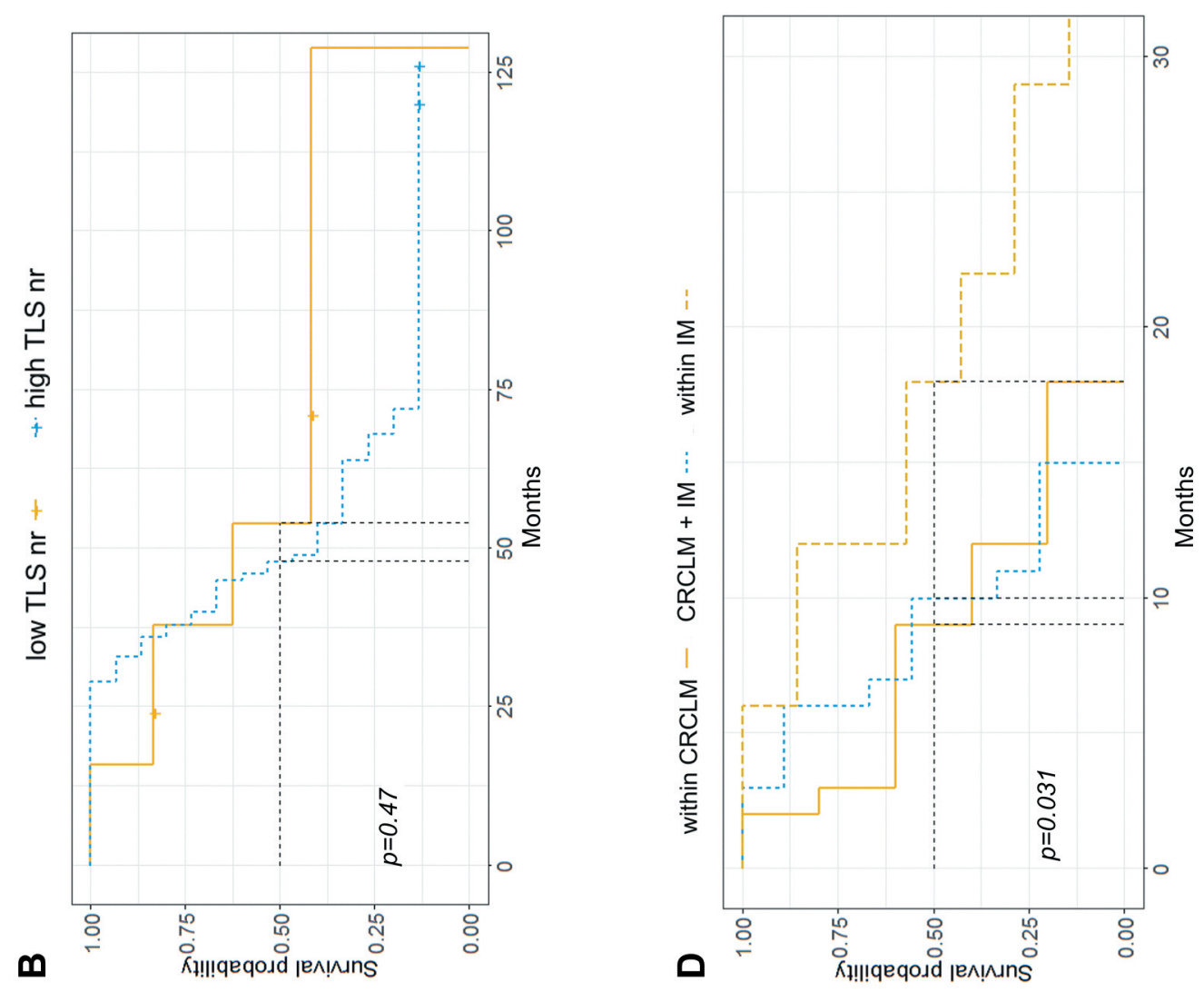

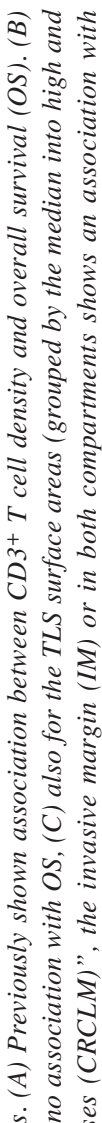
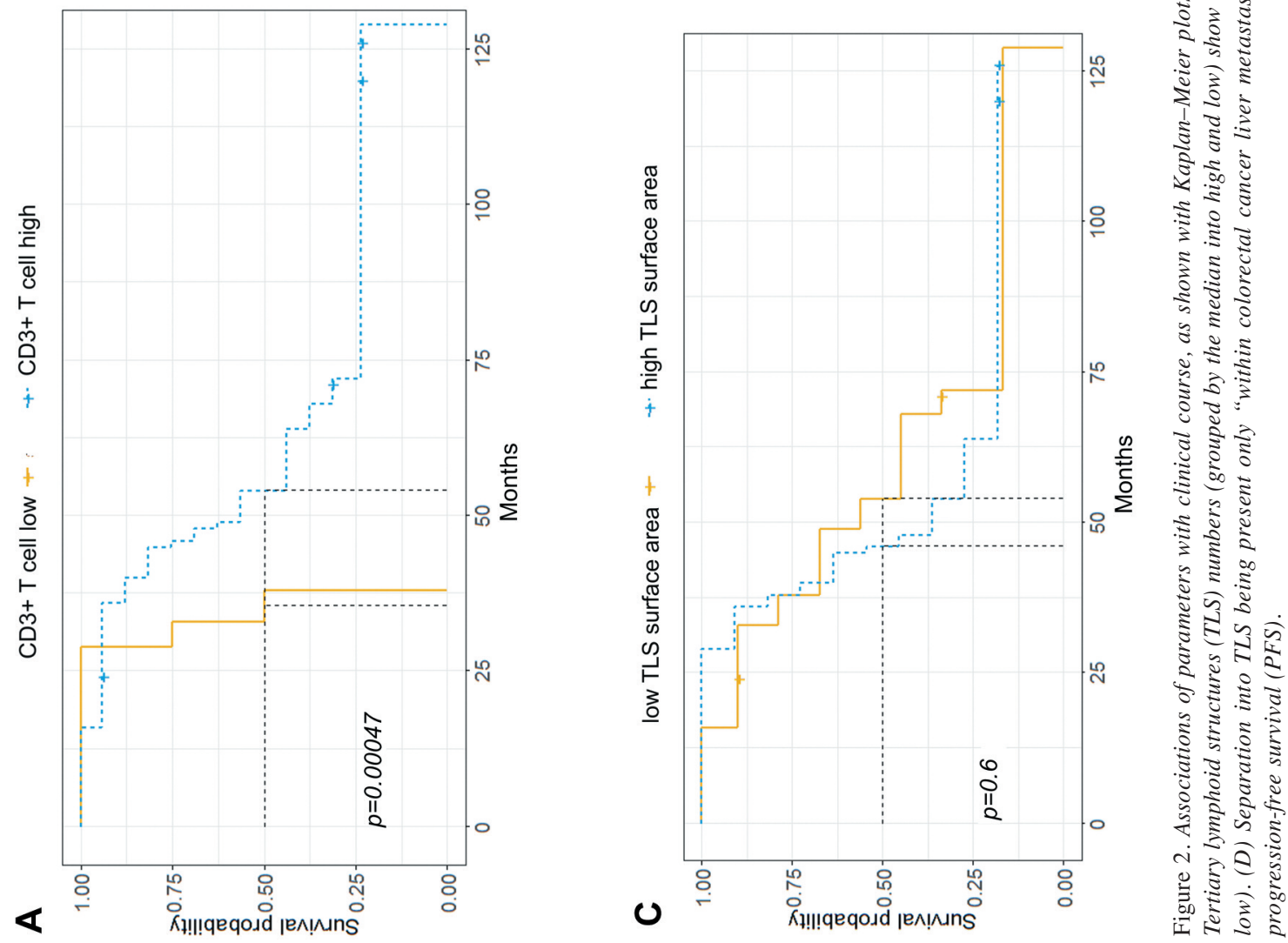
that the composition of the TLS in mCRC differs from the described morphologies in lung cancer, sarcoma and melanoma. The presence of DC-LAMP, a marker for mature dendritic cells, showed negligible positivity in the TLS in CRCLM. As for CD20 (as a marker of B cells), positive cells can be found, but their general localization within the TLS has not the classical "fried egg" composition with an inner circle of $\mathrm{CD} 20^{+} \mathrm{B}$ cells and an outer circle with effector $\mathrm{T}$ cells. Instead, it shows a rather diffuse pattern within the TLS. This is not proof, but at least suggestive of an altered functional status of TLS in CRCLM. Alternatively, it could be a specific effect of the metastatic site: the liver. However, further systematic analyses are required to unravel the functional role of B cells in the context of TLS in CRCLM. Looking into the question whether TLS are independent of the immune cell composition in the microenvironment (26), it was clearly visible that they correlate to the overall density of $\mathrm{CD} 3^{+} \mathrm{T}$ cells. Here, the correlation only explained $\sim 60 \%$ of the cases, thus there are cases where low TLS formation takes place without higher $\mathrm{CD}^{+} \mathrm{T}$ cell densities. There is not enough evidence, but possibly the overall $\mathrm{T}$ cell infiltration in the tissue is limited, while their activation and TLS formation is still possible due to other factors enforcing inflammation (27, 28). Other factors like KRAS mutational status or nodal status of the primary tumor, age and gender were not linked with TLS formation. Thus, if TLS formation is somewhat independent of the T cell composition, is TLS associated with chemotherapy response and can it be an independent biomarker (29)? In our cohort, there was no evidence for such association, which leads to the conclusion that the $\mathrm{CD}^{+}$, $\mathrm{CD}^{+}$and Granzyme $\mathrm{B}^{+} \mathrm{T}$ cell composition is still the key factor. A limitation of this analysis is the small number of patients, with previous findings from this cohort, however, being independently validated by others $(10,30)$. Nevertheless, further studies are needed to clarify these aspects. In summary, we report an altered ultrastructure of TLS in CRCLM and an association with a better clinical course when the TLS are located at the invasive margin of the CRCLM. The presence of TLS is somewhat linked to the overall $\mathrm{T}$ cell density, but other factors like the nodal status of the tumor, age and gender are not associated. Chemotherapy responses were not linked to the presence of TLS in our cohort. More studies are needed to better understand the differential role of TLS in CRC metastases.

\section{Conflicts of Interest}

The Authors declare no competing interests in relation to this study.

\section{Authors' Contributions}

Conceptualization: A.A., N.H.; methodology: A.A., N.H.; formal analysis: N.H.; investigation: A.A., N.H.; resources: N.H.; data curation: N.H.; writing-original draft preparation: A.A., N.H.; writing- review and editing: A.A., N.H.; visualization: A.A., N.H.; supervision: N.H.; project administration: N.H.; funding acquisition: N.H.

\section{Acknowledgements}

The Authors thank Rosa Eurich and Jana Wolf for expert technical assistance.

\section{References}

1 Di Caro G, Bergomas F, Grizzi F, Doni A, Bianchi P, Malesci A, Laghi L, Allavena P, Mantovani A and Marchesi F: Occurrence of tertiary lymphoid tissue is associated with t-cell infiltration and predicts better prognosis in early-stage colorectal cancers. Clin Cancer Res 20(8): 2147-2158, 2014. PMID: 24523438. DOI: 10.1158/1078-0432.CCR-13-2590

2 Di Caro G, Castino GF, Bergomas F, Cortese N, Chiriva-Internati M, Grizzi F, Mantovani A and Marchesi F: Tertiary lymphoid tissue in the tumor microenvironment: From its occurrence to immunotherapeutic implications. Int Rev Immunol 34(2): 123-133, 2015. PMID: 25901857. DOI: 10.3109/08830185.2015.1018416

3 Dieu-Nosjean MC, Giraldo NA, Kaplon H, Germain C, Fridman WH and Sautes-Fridman C: Tertiary lymphoid structures, drivers of the anti-tumor responses in human cancers. Immunol Rev 271(1): 260-275, 2016. PMID: 27088920. DOI: 10.1111/imr.12405

4 Becht E, Giraldo NA, Dieu-Nosjean MC, Sautes-Fridman C and Fridman WH: Cancer immune contexture and immunotherapy. Curr Opin Immunol 39: 7-13, 2016. PMID: 26708937. DOI: 10.1016/j.coi.2015.11.009

5 Kroemer G, Galluzzi L, Zitvogel L and Fridman WH: Colorectal cancer: The first neoplasia found to be under immunosurveillance and the last one to respond to immunotherapy? Oncoimmunology 4(7): e1058597, 2015. PMID: 4485723, DOI: $10.1080 / 216240$ 2X.2015.1058597

6 Fridman WH, Pages F, Sautes-Fridman C and Galon J: The immune contexture in human tumours: Impact on clinical outcome. Nat Rev Cancer 12(4): 298-306, 2012. PMID: 22419253. DOI: $10.1038 / \mathrm{nrc} 3245$

7 Cabrita R, Lauss M, Sanna A, Donia M, Skaarup Larsen M, Mitra S, Johansson I, Phung B, Harbst K, Vallon-Christersson J, van Schoiack A, Lovgren K, Warren S, Jirstrom K, Olsson H, Pietras K, Ingvar C, Isaksson K, Schadendorf D, Schmidt H, Bastholt L, Carneiro A, Wargo JA, Svane IM and Jonsson G: Tertiary lymphoid structures improve immunotherapy and survival in melanoma. Nature 577(7791): 561-565, 2020. PMID: 31942071. DOI: 10.1038/s41586-019-1914-8

8 Helmink BA, Reddy SM, Gao J, Zhang S, Basar R, Thakur R, Yizhak K, Sade-Feldman M, Blando J, Han G, Gopalakrishnan V, Xi Y, Zhao H, Amaria RN, Tawbi HA, Cogdill AP, Liu W, LeBleu VS, Kugeratski FG, Patel S, Davies MA, Hwu P, Lee JE, Gershenwald JE, Lucci A, Arora R, Woodman S, Keung EZ, Gaudreau PO, Reuben A, Spencer CN, Burton EM, Haydu LE, Lazar AJ, Zapassodi R, Hudgens CW, Ledesma DA, Ong S, Bailey M, Warren S, Rao D, Krijgsman O, Rozeman EA, Peeper D, Blank CU, Schumacher TN, Butterfield LH, Zelazowska MA, McBride KM, Kalluri R, Allison J, Petitprez F, Fridman WH, SautesFridman C, Hacohen N, Rezvani K, Sharma P, Tetzlaff MT, Wang $\mathrm{L}$ and Wargo JA: B cells and tertiary lymphoid structures promote immunotherapy response. Nature 577(7791): 549-555, 2020. PMID: 31942075. DOI: 10.1038/s41586-019-1922-8

9 Tanis E, Julie C, Emile JF, Mauer M, Nordlinger B, Aust D, Roth A, Lutz MP, Gruenberger T, Wrba F, Sorbye H, Bechstein 
W, Schlag P, Fisseler A and Ruers T: Prognostic impact of immune response in resectable colorectal liver metastases treated by surgery alone or surgery with perioperative folfox in the randomised eortc study 40983. Eur J Cancer 51(17): 2708-2717, 2015. PMID: 26342674. DOI: 10.1016/j.ejca.2015.08.014

10 Halama N, Michel S, Kloor M, Zoernig I, Benner A, Spille A, Pommerencke T, von KnebelDM, Folprecht G, Luber B, Feyen N, Martens UM, Beckhove P, Gnjatic S, Schirmacher P, Herpel E, Weitz J, Grabe N and Jaeger D: Localization and density of immune cells in the invasive margin of human colorectal cancer liver metastases are prognostic for response to chemotherapy. Cancer Res 71(17): 5670-5677, 2011. PMID: 21846824.

11 Van Cutsem E and Ducreux M: Colorectal and gastric cancer in 2015: The development of new agents and molecular classifications. Nat Rev Clin Oncol 13(2): 69-70, 2016. PMID: 26667973. DOI: $10.1038 /$ nrclinonc.2015.217

12 Veereman G, Robays J, Verleye L, Leroy R, Rolfo C, Van Cutsem E, Bielen D, Ceelen W, Danse E, De Man M, Demetter P, Flamen P, Hendlisz A, Sinapi I, Vanbeckevoort D, Ysebaert D and Peeters M: Pooled analysis of the surgical treatment for colorectal cancer liver metastases. Crit Rev Oncol Hematol 94(1): 122-135, 2015. PMID: 25666309. DOI: 10.1016/j.critrevonc.2014.12.004

13 Kopetz S, Chang GJ, Overman MJ, Eng C, Sargent DJ, Larson DW, Grothey A, Vauthey J-N, Nagorney DM and McWilliams RR: Improved survival in metastatic colorectal cancer is associated with adoption of hepatic resection and improved chemotherapy. J Clin Oncol 27(22): 3677-3683, 2009. PMID: 19470929.

14 Holch JW, Ricard I, Stintzing S, Modest DP and Heinemann V: The relevance of primary tumour location in patients with metastatic colorectal cancer: A meta-analysis of first-line clinical trials. Eur J Cancer 70: 87-98, 2017. PMID: 27907852. DOI: 10.1016/j.ejca.2016.10.007

15 Becht E, Giraldo NA, Germain C, de Reynies A, Laurent-Puig P, Zucman-Rossi J, Dieu-Nosjean MC, Sautes-Fridman C and Fridman WH: Immune contexture, immunoscore, and malignant cell molecular subgroups for prognostic and theranostic classifications of cancers. Adv Immunol 130: 95-190, 2016. PMID: 26923001. DOI: 10.1016/bs.ai.2015.12.002

16 Mlecnik B, Bindea G, Angell HK, Maby P, Angelova M, Tougeron D, Church SE, Lafontaine L, Fischer M, Fredriksen T, Sasso M, Bilocq AM, Kirilovsky A, Obenauf AC, Hamieh M, Berger A, Bruneval P, Tuech JJ, Sabourin JC, Le Pessot F, Mauillon J, Rafii A, Laurent-Puig P, Speicher MR, Trajanoski Z, Michel P, Sesboue R, Frebourg T, Pages F, Valge-Archer V, Latouche JB and Galon J: Integrative analyses of colorectal cancer show immunoscore is a stronger predictor of patient survival than microsatellite instability. Immunity 44(3): 698-711, 2016. PMID: 26982367. DOI: 10.1016/j.immuni.2016.02.025

17 Halama N, Zoernig I, Spille A, Michel S, Kloor M, GraulingHalama S, Westphal K, Schirmacher P, Jager D and Grabe N: Quantification of prognostic immune cell markers in colorectal cancer using whole slide imaging tumor maps. Anal Quant Cytol Histol 32(6): 333-340, 2010. PMID: 21456345.

18 Halama N, Michel S, Kloor M, Zoernig I, Benner A, Spille A, Pommerencke T, von Knebel DM, Folprecht G, Luber B, Feyen N, Martens UM, Beckhove P, Gnjatic S, Schirmacher P, Herpel E, Weitz J, Grabe N and Jaeger D: Localization and density of immune cells in the invasive margin of human colorectal cancer liver metastases are prognostic for response to chemotherapy. Cancer Res 71(17): 5670-5677, 2011. PMID: 21846824. DOI: 10.1158/0008-5472.CAN-11-0268
19 Halama N, Zoernig I, Spille A, Westphal K, Schirmacher P, Jaeger D and Grabe N: Estimation of immune cell densities in immune cell conglomerates: An approach for high-throughput quantification. PLoS One 4(11): e7847, 2009. PMID: 2774165. DOI: 10.1371 journal.pone.0007847

20 Halama N, Braun M, Kahlert C, Spille A, Quack C, Rahbari N, Koch M, Weitz J, Kloor M, Zoernig I, Schirmacher P, Brand K, Grabe $\mathrm{N}$ and Falk CS: Natural killer cells are scarce in colorectal carcinoma tissue despite high levels of chemokines and cytokines. Clin Cancer Res 17(4): 678-689, 2011. PMID: 21325295. DOI: 10.1158/1078-0432.CCR-10-2173

21 Galon J, Costes A, Sanchez-Cabo F, Kirilovsky A, Mlecnik B, Lagorce-Pagès $\mathrm{C}$, Tosolini $\mathrm{M}$, Camus $\mathrm{M}$, Berger $\mathrm{A}$ and Wind $\mathrm{P}$ : Type, density, and location of immune cells within human colorectal tumors predict clinical outcome. Science 313(5795): 1960-1964, 2006. PMID: 17008531.

22 Fridman WH, Pagès F, Sautès-Fridman $\mathrm{C}$ and Galon $\mathrm{J}$ : The immune contexture in human tumours: Impact on clinical outcome. Nat Rev Cancer 12(4): 298-306, 2012. PMID: 22419253. DOI: $10.1038 / \mathrm{nrc} 3245$

23 Sautes-Fridman C, Lawand M, Giraldo NA, Kaplon H, Germain C, Fridman WH and Dieu-Nosjean MC: Tertiary lymphoid structures in cancers: Prognostic value, regulation, and manipulation for therapeutic intervention. Front Immunol 7: 407, 2016. PMID: 5046074. DOI: 10.3389/fimmu.2016.00407

24 de Chaisemartin L, Goc J, Damotte D, Validire P, Magdeleinat P, Alifano M, Cremer I, Fridman WH, Sautes-Fridman C and Dieu-Nosjean MC: Characterization of chemokines and adhesion molecules associated with $\mathrm{t}$ cell presence in tertiary lymphoid structures in human lung cancer. Cancer Res 71(20): 6391-6399, 2011. PMID: 21900403. DOI: 10.1158/0008-5472.CAN-11-0952

25 Halama N, Michel S, Kloor M, Zoernig I, Pommerencke T, von Knebel Doeberitz M, Schirmacher P, Weitz J, Grabe N and Jager D: The localization and density of immune cells in primary tumors of human metastatic colorectal cancer shows an association with response to chemotherapy. Cancer Immun 9: 1, 2009. PMID: 2935770.

26 Halama N: The next age of immunotherapy: Optimisation, stratification and therapeutic synergies. Br J Cancer 120(1): 12, 2019. PMID: 6325151. DOI: 10.1038/s41416-018-0330-4

27 Halama N: Bowel inflammation in cancer patients: The microbiome, antibiotics and interleukin-9. Br J Cancer, 2020. PMID: 32843683. DOI: 10.1038/s41416-020-01030-0

28 Boakye D, Jansen L, Schottker B, Jansen E, Schneider M, Halama N, Gao X, Chang-Claude J, Hoffmeister M and Brenner $\mathrm{H}$ : Blood markers of oxidative stress are strongly associated with poorer prognosis in colorectal cancer patients. Int J Cancer, 2020. PMID: 32319674. DOI: 10.1002/ijc.3301

29 Halama $\mathrm{N}$ and Haberkorn U: The unmet needs of the diagnosis, staging, and treatment of gastrointestinal tumors. Semin Nucl Med 50(5): 389-398, 2020. PMID: 32768003. DOI: 10.1053/j.sem nuclmed.2020.06.003

30 Dahlin AM, Henriksson ML, Van Guelpen B, Stenling R, Öberg Å, Rutegård J and Palmqvist R: Colorectal cancer prognosis depends on t-cell infiltration and molecular characteristics of the tumor. Mod Pathol 24(5): 671-682, 2011. PMID: 21240258.

Received September 21, 2020

Revised October 1, 2020

Accepted October 2, 2020 